\title{
EDITORIAL
}

\section{SUPERNOVA: will its energy trigger the formation of a new therapeutic star?}

\author{
Thomas Bein ${ }^{1 *}\left(\mathbb{D}\right.$, Audrey De Jong ${ }^{2}$ and Anders Perner ${ }^{3}$
}

๑ 2019 Springer-Verlag GmbH Germany, part of Springer Nature

In 1983, Luciano Gattinoni had the vision of a 'motionless lung' [1] with the help of an extracorporeal carbon dioxide elimination concept. At that time the term VILI (ventilator induced lung injury) was still far beyond the horizon and no intensivist or respiratory therapist anticipated the consequences of the ARDS Network study from 2000 [2], which began to hold a mirror up to the intensive care community in terms of a protective approach to the injured lung. Did no intensivist or respiratory therapist really anticipate this? The answer is just a few around Gattinoni who stated in 1978 "that patients treated with mechanical ventilation ultimately die, either of the underlying disease process or of complications of pulmonary therapy with mechanical ventilation" [3]. In the late 1990s, a long and partly successful story began on lung protective strategies aimed at saving lives by preventing the deleterious effects of artificial ventilation. Why only partly successful? The answer seems simple, but it is not: the reduction of tidal volume and inspiratory pressure levels was helpful, but it was not the definitive solution to the dilemma between the necessity of mechanical ventilation (to guarantee a life-saving gas exchange) and the attenuation of its harmful effects. In other words, the low tidal volume strategy combined with a limitation of inspiratory pressures went in the right direction, but the clinical scientists continued to ask: "Is there a safe upper limit to inspiratory plateau pressure in patients with ALI/ ARDS?" [4].

In 2009, stimulated by the CESAR trial [5], the technique of extracorporeal membrane oxygenation (ECMO) celebrated a triumph, which continues to this day [6]:

*Correspondence: thomas.bein@ukr.de

${ }^{1}$ Department of Anesthesia, University Hospital Regensburg, 93042 Regensburg, Germany

Full author information is available at the end of the article the concept of extracorporeal carbon dioxide removal (ECCO2-R), the little sister of ECMO, reanimated Gattinoni's vision of 'motionless lungs'. In contrast to fullblown ECMO, the ECCO2-R technique is characterized by lower extracorporeal blood flow rates between 400 and $1000 \mathrm{ml} / \mathrm{min}$ in combination with smaller cannulae promising less complications [7]. The effectiveness of such a strategy regarding carbon dioxide removal in substantial amounts has been demonstrated in several experimental studies [8,9]; with this technique, Gattinoni's vision was modified to the possibility of 'super-protective' [10] ventilation allowing 'near-motionless' lungs. The first controlled trial with the use of ECCO2-R combined with the concept of lung protection randomized 79 patients with ARDS to a very low tidal volume $(\mathrm{VT})$ strategy $[\approx$ $3 \mathrm{ml} / \mathrm{kg}$ predicted body weight (PBW)] combined with pumpless arterio-venous ECCO2-R, or to lower ARDS Network standard VT ventilation $(\approx 6 \mathrm{ml} / \mathrm{kg}$ PBW) without the extracorporeal device [11]. In that trial, the concept of ventilation with very low VT appeared to work, but some adverse events were observed. Although the overall number of ventilator-free days and mortality rates were not different between the two intervention groups, a post hoc analysis suggested fewer ventilator-free days at 60 days with ECCO2-R in patients with severe hypoxemia $\left(\mathrm{PaO}_{2} / \mathrm{FIO}_{2}\right.$ ratio $\left.<150\right)$.

Another feasibility trial of ECCO2-R (SUPERNOVA) aiming at (ultra)-protective ventilation was recently published in Intensive Care Medicine [12]. This trial enrolled 95 patients with ARDS; the primary endpoint was the proportion of patients achieving an ultra-protective level of low VT ventilation (reduction of VT to $4 \mathrm{ml} / \mathrm{kg}$ and a target $P_{\text {Plat }}$ of $\leq 25 \mathrm{cmH}_{2} \mathrm{O}$ ) using various veno-venous ECCO2- $\mathrm{R}$ devices allowing extracorporeal blood flows between $300 \mathrm{ml} / \mathrm{min}$ (lower extraction) and $1000 \mathrm{ml} /$ min (higher extraction). The primary endpoint was achieved within 8 h by $78 \%$ and within 24 h by $82 \%$ of

\section{Springer}




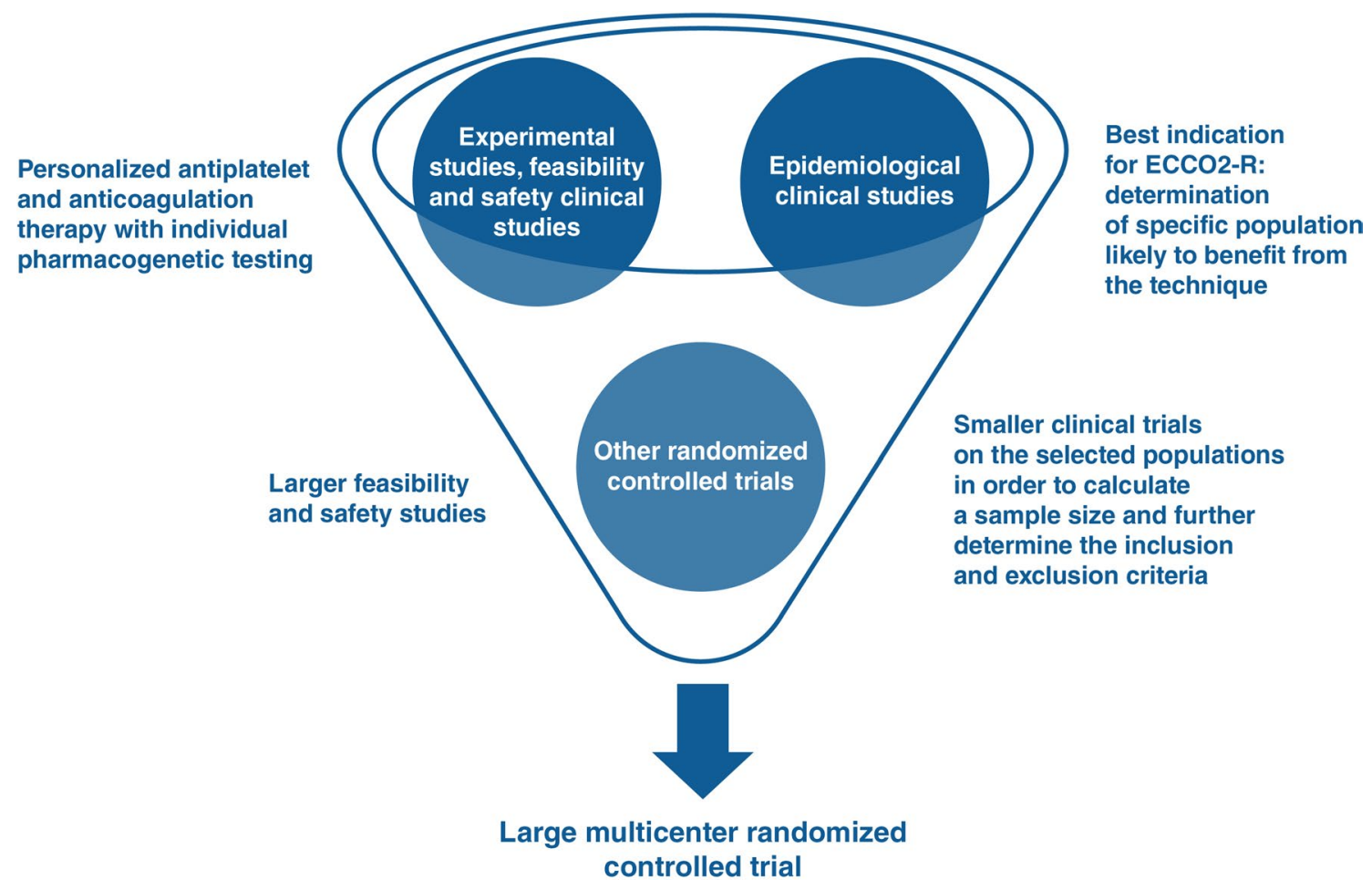

Fig. 1 An agenda for the initiation of a large multicenter randomized ECCO2-R study

the participants. Again, ECCO2-R-related adverse events were observed (catheter displacement or infectious complications in $2 \%$ and membrane lung clotting or bleeding in $14 \%$, highlighting the coagulation/anticoagulation balance as most problematic).

Is evidence for feasibility (and safety!) of ECCO2-R provided with these results? Feasibility is defined as a "state or degree of being easily or conveniently done" [13]. It is debatable whether a substantial number of participants with coagulation problems-be it clotting or bleeding-allows a statement that ultra-protective ventilation using ECCO2-R devices is easily or conveniently applied. The unsolved problem of a targeted balance of anticoagulation-allowing low extracorporeal blood flow and simultaneously avoiding clotting or bleeding complications-requires further careful experimental and clinical studies before planning a "well-designed randomized clinical trial" (Fig. 1), as requested by the authors of the SUPERNOVA trial paper. It may be that a personalized antiplatelet and anticoagulation strategy is needed [14]. With the development of such newer strategies using individual pharmacogenetic and pharmacodynamic testing, important information could be provided to assist intensivists with the best antiplatelet and anticoagulation therapy, which could replace the 'good old' activated partial thromboplastin time (aPTT) as a non-specific and insensitive marker for optimal coagulation balance in the individual ECCO2-R patient. Similarly, the selection of the population most likely to benefit from ECCO2$\mathrm{R}$ therapy is crucial; from no-ARDS patients to mild or moderate or moderate to severe ARDS patients, further studies are still needed to inform about the better population.

SUPERNOVA is not yet ready to trigger a new stara lot of work must be done before a next 'feasibility and safety' study. Supernovas can indicate the sudden gravitational collapse of a massive star's core, or they can trigger the formation of a new star. We hope the latter will happen!

\section{Author details}

${ }^{1}$ Department of Anesthesia, University Hospital Regensburg, 93042 Regensburg, Germany. ${ }^{2}$ University of Montpellier, INSERM U1046, CNRS UMR 9214, Anesthesia and Critical Care Department B, Saint Eloi Teaching Hospital, Centre Hospitalier Universitaire Montpellier, Montpellier cedex 5, France.

${ }^{3}$ Department of Clinical Medicine Rigshospitalet, Center for Kræft og Organsygdomme, Blegdamsvej 9, 2100 Copenhagen, Denmark.

Compliance with ethical standards

\section{Conflicts of interest}

TB declares no conflicts of interest. ADJ reports personal fees from Baxter and Medtronic, and travel reimbursements from Fresenius-Kabi, MSD France, Astellas, Pfizer and Fisher Paykel. AP department receives support for research from Ferring Pharmaceuticals and the Novo Nordisk Foundation. 


\section{Publisher's Note}

Springer Nature remains neutral with regard to jurisdictional claims in published maps and institutional affiliations.

Received: 29 April 2019 Accepted: 6 May 2019

Published online: 20 May 2019

\section{References}

1. Gattinoni L, Pesenti A, Kolobow T, Damia G (1983) A new look at therapy of the adult respiratory distress syndrome: motionless lungs. Int Anesthesiol Clin 21(2):97-117

2. Acute Respiratory Distress Syndrome Network, Brower RG, Matthay MA, Morris A, Schoenfeld D, Thompson BT, Wheeler A (2000) Ventilation with lower tidal volumes as compared with traditional tidal volumes for acute lung injury and the acute respiratory distress syndrome. N Engl J Med 342:1301-1308

3. Gattinoni L, Kolobow T, Tomlinson T, lapichino G, Samaja M, White D, Pierce J (1978) Low-frequency positive pressure ventilation with extracorporeal carbon dioxide removal (LFPPV-ECCO2R): an experimental study. Anesth Analg 57(4):470-477

4. Hager DN, Krishnan JA, Hayden DL, Brower RG, ARDS Clinical Trials Network (2005) Tidal volume reduction in patients with acute lung injury when plateau pressures are not high. Am J Respir Crit Care Med 172(10):1241-1245

5. Peek GJ, Mugford M, Tiruvoipati R, Wilson A, Allen E, Thalanany MM, Hibbert CL, Truesdale A, Clemens F, Cooper N, Firmin RK, Elbourne D, CESAR Trial Collaboration (2009) Efficacy and economic assessment of conventional ventilatory support versus extracorporeal membrane oxygenation for severe adult respiratory failure (CESAR): a multicentre randomised controlled trial. Lancet 374(9698):1351-1363

6. Karagiannidis C, Brodie D, Strassmann S, Stoelben E, Philipp A, Bein T, Müller T, Windisch W (2016) Extracorporeal membrane oxygenation: evolving epidemiology and mortality. Intensive Care Med 42:889-896
7. Morelli A, Del Sorbo L, Pesenti A, Ranieri VM, Fan E (2017) Extracorporeal carbon dioxide removal $\left(\mathrm{ECCO}_{2} \mathrm{R}\right)$ in patients with acute respiratory failure. Intensive Care Med 43:519-530

8. Karagiannidis C, Kampe KA, Sipmann FS, Larsson A, Hedenstierna G, Windisch W, Mueller T (2014) Veno-venous extracorporeal $\mathrm{CO}_{2}$ removal for the treatment of severe respiratory acidosis: pathophysiological and technical considerations. Crit Care 18:R124

9. Karagiannidis C, Hesselmann F, Fan E (2019) Physiological and technical considerations of extracorporeal $\mathrm{CO}_{2}$ removal. Crit Care 23(1):75

10. Schultz MJ, Juffermans NP, Matthay MA (2013) From protective ventilation to super-protective ventilation for acute respiratory distress syndrome. Intensive Care Med 39:963-965

11. Bein T, Weber-Carstens S, Goldmann A, Müller T, Staudinger T, Brederlau J, Muellenbach R, Dembinski R, Graf BM, Wewalka M, Philipp A, Wernecke KD, Lubnow M, Slutsky AS (2013) Lower tidal volume strategy $(\approx 3 \mathrm{ml} / \mathrm{kg})$ combined with extracorporeal CO2 removal versus 'conventional' protective ventilation $(6 \mathrm{ml} / \mathrm{kg})$ in severe ARDS: the prospective randomized Xtravent-study. Intensive Care Med 39:847-856

12. Combes A, Fanelli V, Pham T, Ranieri VM, European Society of Intensive Care Medicine Trials Group, and the "Strategy of Ultra-Protective lung ventilation with Extracorporeal CO2 Removal for New-Onset moderate to severe ARDS" (SUPERNOVA) Investigators (2019) Feasibility and safety of extracorporeal $\mathrm{CO}_{2}$ removal to enhance protective ventilation in acute respiratory distress syndrome: the SUPERNOVA study. Intensive Care Med. https://doi.org/10.1007/s00134-019-05567-4

13. English Oxford Living Dictionaries. https://en.oxforddictionaries.com/ definition/feasibility. Accessed date 25 Apr 2019

14. Beitelshees AL, Voora D, Lewis JP (2015) Personalized antiplatelet and anticoagulation therapy: applications and significance of pharmacogenomics. Pharmgenomics Pers Med 8:43-61 